\title{
Escrita e municipalismo na transição do Brasil colônia e na ideação do Brasil independente
}

\section{Writing and municipalities in the transition from colony to independence in Brasil}

\author{
Justino Magalhães*
}

\begin{abstract}
Resumo
A história das câmaras municipais inclui funções de representação, integração, preservação da identidade, fomento do local. Os concelhos eram instâncias judiciais, governativas, econômicas; ao desenvolverem-se, os concelhos tornaram-se também sociais, culturais, pedagógicos. A estrutura concelhia foi primordial na política, na administração e na escrituração da sociedade colonial. Serviu os interesses da coroa e serviu o interesse das elites locais. Na transição do Brasil colônia, os municípios representaram e congregaram as forças vivas locais no caminho do progresso, da reforma do Estado e na conquista da soberania. Deram ânimo e sentido às mudanças, construindo um lema para a vontade política - sentimento nacionalista. 0 Brasil independente reservou aos municípios um excepcional e inovador papel no fomento da escolarização.
\end{abstract}

Palavras-chaves: Município. Brasil colônia. Escrituração municipal. Escritaprocesso sociopolítico. Ideação do Brasil independente.

\begin{abstract}
The history of municipal councils includes representation functions, integration, identity preservation, promotion of the localities. Municipalities were legal, governmental, economic instances, and they have also become social, cultural, educational. The district council structure was paramount in politics, administration and bookkeeping of colonial society. Served the interests of the State and served the interests of local elites. In the transition from Brazil-colony, municipalities represented and gathered local movers in the way of progress, reform of the State and the realization of sovereignty.
\end{abstract}

\footnotetext{
* Doutor em Educação pela Universidade do Minho. Professor Catedrático do Instituto de Educação da Universidade de Lisboa. E-mail: justinomagalhaes@ie.ulisboa.pt. Este texto é resultado do Projeto Atlas-Repertório dos Municípios na Educação e na Cultura em Portugal (1820-1986), que tem vindo a resgatar aspectos significativos da municipalização e do municipalismo português na aculturação escrita e no fomento da instrução e da cultura, é financiado pela Fundação para a Ciência e a Tecnologia - FCT/Ref. PTDC/CPE-CED/116938/2010.
} 
They gave encouragement and direction to changes, making a slogan for political will - nationalist sentiment. Independent Brazil reserved to municipalities exceptional and innovative role in promoting schooling.

Key Words: Municipality. Brazil-colony. Municipal bookkeeping. Writingprocess social-political. Ideation of independent Brazil.

\section{O Município como unidade orgânica}

O município é a entidade histórica formada por um território, uma população, uma economia, uma tradição, uma cultura. Tem por base um contrato de legitimidade de poder e de representação, fundamentado nas noções de autarcia e desenvolvimento. Reporta à administração do local, constituída por um concelho composto por órgãos de legislação, governo e fiscalização, nomeadamente, câmara, vereadores, procuradores, zeladores. Historicamente, as câmaras municipais assumiram funções de representação, integração, preservação da identidade, fomento do local. Ao desenvolver-se, o município assumiu funções judiciais, governativas, econômicas, sociais, culturais, pedagógicas. A estrutura concelhia foi primordial na política e na administração da sociedade colonial. Serviu os interesses da coroa, mas serviu também o interesse das elites locais.

Maria Fernanda Bicalho, ${ }^{1}$ retomando as teses de C. R. Boxer, sustenta que "as câmaras foram instituições fundamentais na construção e na manutenção do Império Ultramarino". ${ }^{2}$ As Câmaras constituíam um modelo administrativo colegial e representativo que, no essencial, manteve uniformidade nas diferentes zonas do Império Colonial. Como relembra Bicalho, para Boxer, as câmaras "se constituíram nos pilares da sociedade colonial portuguesa desde o Maranhão até Macau, pois garantiam uma continuidade que governadores, bispos e magistrados passageiros não podiam assegurar". ${ }^{3}$ As câmaras eram uma das vias de acesso à nobilitação dos colonos, transformando-os em cidadãos do Império; nos termos do Alvará régio de 12 de Novembro de 1611, a escolha dos eleitores deveria recair sobre "os mais nobres e da governança da terra". ${ }^{4}$

\footnotetext{
${ }^{1}$ BICALHO, Maria Fernanda. "As câmaras ultramarinas e o governo do Império", in: FRAGOSO, João; BICALHO, Maria Fernanda e GOUVÊA, Maria de Fátima (orgs). 0 Antigo Regime nos Trópicos: A dinâmica imperial portuguesa (séculos XVI-XVIII). 2ª edição. Rio de Janeiro: Civilização Brasileira, 2010, p. 189-221.

${ }^{2}$ Ibidem, p. 191.

${ }^{3}$ Apud Bicalho, p. 191.

${ }^{4}$ Apud Bicalho, p. 207.
} 
Desde D. João III que o município era a instância judicial principal no Brasil, associada à polarização urbana, à concentração e administração de bens, ao controlo do comércio. 0 incremento da fundação de vilas e concelhos foi acelerado nas primeiras décadas do século XVIII, reforçando o controlo e a representação régia, nomeadamente nas regiões mineiras. A estrutura municipal continha um quadro orgânico e administrativo que se adequava às necessidades e às principais prerrogativas políticas, jurídicas, econômicas e de representação do local. O município político-administrativo dispunha de órgãos de poder, colegiais e unipessoais. Os primeiros eram eleitos e os titulares dos segundos ora foram eleitos, ora designados, em conformidade com as diferentes épocas e os respectivos quadros administrativos. A escrituração municipal foi configurada de modo a privilegiar as funções orgânica e administrativa.

\section{O município como realidade histórica}

A salvaguarda dos interesses da coroa no império forçou à criação e manutenção de uma administração escrita, cultivada e praticada por oficiais letrados, conforme comprova a Informação do Procurador da Fazenda ao Conselho Ultramarino, de 10 de Novembro de 1699:

Conhecendo os descaminhos que tinha a Fazenda Real que administra a câmara, assim na arrecadação como na despesa, que só poderiam ter remédio havendo Juiz de Fora que nela presidisse, além da grande conveniência dos povos, sendo a justiça assim no criminal, como no cível administrada por Ministro letrado, estranho e pendente de residência e melhoramento, e não por leigo, natural, e absoluto daquelas obrigações (...) desde que procuro pela Fazenda Real, clamo por este remédio que Sua Majestade foi servido conceder à Bahia, e agora quer dar a Pernambuco, e espero que também dê ao Rio de Janeiro. ${ }^{5}$

O concelho era a instituição que congregava a existência de uma justiça régia-letrada, confiada ao Juiz de Fora, com um governo colegial e com uma força policial, pelo que permitia assegurar a representatividade interna e salvaguardar, em simultâneo, os interesses da coroa num quadro de desenvolvimento articulado. Nos termos das Ordenações Manuelinas, constituía uma entidade jurídica e administrativa adaptável à realidade colonial. No Brasil, cuja colonização contou com comunidades de colonos que aspiravam ao reconhecimento régio para o exercício da soberania nos territórios ocu-

\footnotetext{
${ }^{5}$ Apud BICALHO, Maria Fernanda. A Cidade e o Império. O Rio de Janeiro no século XVIII. Rio de Janeiro: Civilização Brasileira, 2003, p. 349.
} 
pados (o que implicava também a relação com as populações autóctones), particularmente a partir de D. João III, a instância municipal tornou-se a estrutura governativa mais frequente. $O$ equilíbrio de poderes, entre o judicial e o executivo, foi frequentemente objeto de disputa e de exorbitação por parte dos concelhos, que estavam apoiados num poder colegial e de representação. Uma dessas situações é descrita e ficou comprovada pela Ordem de 13 de Novembro de 1732:

(...) se ordena ao governador que mande prender os vereadores da Vila do Carmo, Manuel Ferraz, João Corrêa da Silva e José Pereira da Costa, por tempo de um mês, na cadeia de Vila Rica, chamando-os no fim do referido tempo à sua presença e que os repreenda severamente pela desatenção que obraram com o juiz de fora da dita Vila do Carmo, declarando-lhes que, estando em ato de Câmara, toca a eles, vereadores, somente votarem nas matérias que se propuserem, e que ao juiz de fora presidente da Câmara toca o mandar entrar e sair da mesma Câmara e o fazer executar todas as disposições que na mesma Câmara se estabelecerem. E que Sua Majestade é servido mandá-los suspender de poderem entrar nas vereações até mercê sua. 0 excesso dos vereadores foi o instarem, estando em ato de Câmara ao juiz de fora António Freire da Fonseca Osório, com vozes alteradas, que se devia suspender o despacho para entrar dentro o almotacé Francisco Xavier da Silva para requerer o (...) fizessem conservar na posse em que estava de prender e soltar, e, entrando com efeito e não querendo consentir o dito juiz de fora, mandaram sair o dito almotacé sem atenção ao mesmo juiz. ${ }^{6}$

Na segunda metade do século XVIII, o poder concelhio foi extensivo à generalidade dos assuntos do poder local. A creditação e o licenciamento dos ofícios mecânicos, bem como os dos ofícios letrados, foi prerrogativa das câmaras. Cabia também às câmaras municipais estipular e fazer cumprir os emolumentos e gratificações a que aqueles oficiais mecânicos e os oficiais letrados tinham direito. Isto mesmo se conclui através da Ordem de 8 de Maio de 1733:

(...) se ordena que o governador, ouvindo os ministros do seu governo e os oficiais das câmaras e os escrivães das mesmas façam uma taxa de salários que devem levar os ditos escrivães, atendendo ao estado da terra e tempo presente, na parte em que não estiverem determinados por lei ou regimento, dando conta e fazendo praticar em tanto o estilo que havia. ${ }^{\text {? }}$

\footnotetext{
${ }^{6}$ Apud BOSCHI, Caio C. (org. e estudo crítico). Coleção Sumária e as próprias leis, carta régias, avisos e ordens que se acham nos livros da Secretaria do Governo desta Capitania de Minas Gerais, reduzidas por ordem a títulos separados. Belo Horizonte: Secretaria de Estado de Cultura de Minas Gerais/ Arquivo Público Mineiro, 2010, p. 165.
}

${ }^{7}$ Apud Ibidem, p. 119-120. 
Também o reconhecimento do poder de decisão das câmaras coloniais ressalta da interpretação da Carta régia de 27 de Julho de 1736, ordenada para prevenir o descaminho e mandando que uma parte das rendas das câmaras de Minas Gerais "se empregue (...) no aumento e conservação do bem público". ${ }^{8}$ As prerrogativas e as atribuições camarárias foram matéria de preocupação e protecção régia, como dispositivo de colonização e organização territorial. É o que ficou estipulado através da Ordem régia enviada à Câmara de Mariana, em 2 de Maio de 1746, pela qual deveriam retornar à Câmara as terras que estavam aforadas pela Fazenda Real, ficando a Câmara obrigada a "edificar casas, fazendo planta e demarcando as ruas, que fiquem direitas e com bastante largura, sem atenção às conveniências particulares ou a edifícios que contra esta ordem se acharem feitos, e que se aforem as braças de terras que os moradores pedirem". ${ }^{9}$

A liberalização de algumas profissões foi frequentemente objeto de contencioso, quer entre as câmaras e as corporações, quer diretamente com os próprios profissionais, que se viam forçados a solicitar a intervenção da coroa. Tal se infere pelos termos em que foi emitida a já mencionada Ordem de 2 de Maio de 1746, onde se declara que "a nomeação de cirurgião do partido da Câmara da cidade de Mariana deve ficar livre aos oficiais da mesma Câmara". ${ }^{10}$

\section{Uma administração escrita}

No Brasil colonial, como refere Fernando Novais, "entre a massa escrava e o senhoriato, toda uma heterogênea e flutuante camada de funcionários, profissionais liberais, plebe urbana etc. tende a tornar mais complexo o quadro de tensões no encaminhamento do processo [do Estado reformista ilustrado], a partir da governação pombalina". ${ }^{11}$ A estrutura concelhia e a economia colonial assentavam na escrita. Parte significativa da referida "camada de funcionários, profissionais liberais" era formada por oficiais da escrita. De modo análogo, parte significativa da plebe urbana era alfabetizada e estava habilitada a fazer uso autônomo da leitura e da escrita. A escrituração era informação, ordem, hierarquia, mobilização. No processo

\footnotetext{
${ }^{8}$ Ibidem, p. 165.

${ }^{9}$ Ibidem, p. 169.

${ }^{10}$ Ibidem.

${ }^{11}$ NOVAIS, Fernando A. Aproximações. Estudos de História e Historiografia. São Paulo: Cosac Naify, 2005, p. 190.
} 
de modernização da administração, a estrutura e a escrita concelhias foram tomadas como referência e como modelo.

O imposto de capitação dos escravos, criado pela intendência de Martinho de Mendonça, era um imposto indireto, que incidia sobre a tributação por escravo alistado, por fazenda ou por oficina. Era uma modalidade de administração letrada e contava com intendentes próprios. A escrituração fazia parte da jurisdição das comarcas e dos municípios, como comprova a Ordem de 28 de Novembro de 1750. Nesta Ordem, ficou determinado que em todas as comarcas do Brasil em que houvesse intendentes da capitação letrados e não houvesse juízes de fora atuais, aqueles substituíssem os ouvidores nas suas faltas. ${ }^{12}$ Os escrivães eram oficiais sempre presentes, acompanhando os detentores de poder, agindo em representação, ou sendo eles próprios autoridade delegada. Assim o comprovam as nomeações de juiz e escrivão para as minas de Itajubá (30 de Dezembro de 1754). 0 mesmo tipo de nomeações ocorreu em Aiuruoca (26 de Setembro de 1758) e quando da criação de novo juiz e escrivão para a Barra do Rio das Velhas (20 de Abril de 1763).

\section{A escrita como processo sociopolítico}

A escrita é um meio de conhecimento, de ciência, de divulgação de ideias e de informação, que se inscreve como transformação em diferentes aspectos do Antigo Regime. Os vínculos históricos de império-colônia e de modernização econômica, política e administrativa, de formação escolar e de configuração intelectual tinham aproximado as sociedades portuguesa e brasileira, muito particularmente desde finais do século XVII. A aculturação escrita tinha feito um caminho, em tudo paralelo, nos planos institucional e formal, na produção do conhecimento, na divulgação cultural, na escrituração de negócios e dos destinos de vida de uns e outros. A escrita foi meio de articulação e comunicação entre os dois lados do Atlântico. Os assuntos religiosos, jurídicos, mercantis, os contratos e os protocolos eram registados e escritos. A escrita dava curso a fórmulas e pragmáticas que corporações de oficiais legitimavam, chancelavam, transmitiam. A escrita cumpria distintas funções e apresentava diferentes tipos, configurações e modalidades de registo.

O concelho resultava de um ato fundante, devidamente selado e legitimado pela escrita. Era um compromisso público formalizado e vinculativo das partes e dos indivíduos, através de assinaturas e de públicos-sinais. 0

${ }^{12}$ BOSCHI, op. cit., p. 90. 
concelho e a escrituração camarária, principalmente nas regiões auríferas, estabeleciam normas; estas deveriam ser aprovadas pelos delegados da coroa e reconhecidas pelos representantes do setor letrado e do setor produtivo. Tais regras comprometiam igualmente os vereadores e os deputados, enquanto representantes da população. A escrita municipal era uma escrita formal, regulamentada pelas Ordenações e por jurisdição régia, e por posturas e vereações, geradas pelas autoridades delegadas e pelos poderes colectivos, a nível local. A escrituração municipal era produto acumulado de gerações de oficiais e de corporações de escrivães, que transmitiam as competências caligráficas e asseguravam a deontologia profissional de geração para geração.

No trânsito do Antigo Regime, a escrita foi também um instrumento ideológico, literário, testamentário, que comportava memórias, arquivos e tombos. Mas foi também um instrumento estatístico, de projeção e planificação, de ideação e um veículo de propaganda e de mobilização dos revolucionários. A escrita-manifesto serviu de instrumento ideológico e agregador, tendo estado na base de intentonas, sedições, Inconfidências. A escrita fez parte do caminho para Independência.

\section{Municipalismo e fomento local}

Território, espaço de integração e de identidade, instância de governo e de fomento do local, os municípios eram constitutivos da esfera pública. Eles eram esfera pública, com capacidade para a organização territorial e a concepção de projetos. Detinham poder político e econômico para assegurar a realização de empreendimentos comunitários, fossem de natureza material, fossem de âmbito cultural e educativo. É o que fica ilustrado com a deliberação da Câmara de Caeté, da Comarca do Rio das Velhas, da qual a seguir se transcrevem alguns passos. ${ }^{13}$ Por convocatória do Escrivão do Senado, no dia 23 de Janeiro de 1816, acorreram aos Paços do Concelho, em Ato de Vereação: os Juízes Ordinários presidentes; o Coronel José de Bitancurt; Luis Soares de Gouveia; as pessoas da Governança; Homens Bons do Povo. Tinham por intento "assentar nos meios mais louvados que se devem seguir para conclusão de uma Estrada que há-de seguir desta vila para a de Sabará". Em face desta incumbência, "acordaram por unânime consentimento dos povos de contribuírem (...) com a taxa que for imposta por este Senado

\footnotetext{
${ }^{13}$ Arquivo Histórico Mineiro, Câmara Municipal de Caeté, Acor 15. Registros de Autos de Vereação, Acórdãos e Termos de Vereança da Câmara Municipal de Caeté, 1816, p. 13-15.
} 
(...) mandando-se passar Editais para até o fim de março entrarem todas as somas que voluntariamente se oferece". Na sequência desta deliberação, a obra deveria ter início no primeiro dia de Abril. Os que concorressem ficariam isentos da "contribuição para dita estrada". Do termo constam mais de trinta assinaturas, entre as quais, as das pessoas "da Governança e Bons do Povo".

A essa Vereação extraordinária acorreram as autoridades instituídas, as principais individualidades, os Homens Bons do Povo. Muitos dos que não puderam estar presentes manifestaram por escrito o seu voto. As Câmaras tinham a faculdade de congregarem as vontades dos diferentes sectores da sociedade. Tal atribuição e esta faculdade foram decisivas em momentos críticos, quer no quadro local e regional, quer em assuntos de âmbito nacional.

A participação camarária era a primeira via de inclusão e de ação cívica, mas era também a primeira instância de não-participação e de alheamento. Assim, ainda que a referida Vereação da Câmara de Caeté tenha sido convocada extraordinariamente e com o objectivo específico de deliberar em matéria de arrecadação de verbas para a construção da estrada que ligava a Sabará, tal deliberação afetava não só os potenciais contribuintes como, também, os prestadores de serviços, forçados a fazê-lo sob a modalidade de jornada gratuita (corveia). Sendo suposto que boa parte destes serviçais e adjudicadores de serviços não eram assinantes, ou eram tão-só assinantes de cruz, a verdade é que não há assinaturas de cruz nas mais de três dezenas constantes do presente termo de Vereação. Em boa verdade, estes prestadores de serviços não participaram da deliberação.

A intervenção no plano da educação traduzia-se, em sentido amplo, na estipulação de regras, pragmáticas, modos de estar e agir, com possibilidade de estabelecer coimas e, no plano mais diretamente escolar, conceder autorização para a abertura de Cadeiras de Primeiras Letras e para a abertura de Escolas de Estudos Menores. Com a criação de um proto sistema escolar a partir da legislação pombalina, sendo os professores régios pagos por verbas do Subsídio Literário (imposto criado exclusivamente para esse efeito e na cobrança do qual intervinham as câmaras municipais), foram frequentes as representações camarárias para que fossem criadas Cadeiras de Primeiras Letras. É o que documenta o Decreto de 2 de Maio de 1816, dando satisfação a uma representação apresentada pela Câmara da Vila de Inhambuque de Cima, na Capitania da Bahia. Eis a referida autorização régia:

Querendo subministrar os meios de instrução precisa à mocidade na Villa de Inhambuque de Cima, na Capitania da Bahia, que actualmente tem crescido 
em povoação, e riqueza, e pela grande extensão do seu termo não pode sem grave incómodo utilizar-se das escolas estabelecidas das vilas vizinhas: Hei por bem, deferindo a representação que a este respeito me fez a Câmara da mesma vila, criar nela duas cadeiras, uma de primeiras letras e outra de gramática latina, com ordenado estabelecido pelas minhas reais ordens para os professores de outras cadeiras desta natureza em lugares semelhantes. A Mesa do Desembargo do Paço tenha assim entendido e faça executar. Palácio do Rio de Janeiro em 2 de Maio de 1816.

\section{Os municípios na ideação do Brasil independente}

No trânsito do Antigo Regime, os municípios eram a principal instância de representação e administração da "coisa" pública, estatuto que foi retomado pelas autoridades revolucionárias e reformadoras do Regime Liberal. Com a laicização e a emergência do civil, o formalismo religioso recuou, tendendo a ser substituído por hábitos de vida urbana, por regras e protocolos de denominação, deferência e comunicação, associados aos municípios. Este reformismo convergia para o núcleo urbano, e o município tornava-se representativo das diferentes instâncias, organismos e poderes no território concelhio.

Um dos aspectos mais característicos da transformação que conduziu ao declínio do Antigo Regime e tornou possível a revolução política foi a vulgarização da comunicação escrita, como meio de mobilização e de criação de opinião. A procura da aculturação escrita fez com que, com a implantação do Regime Liberal, as questões da instrução pública tivessem assumido uma centralidade que as tornou prerrogativa do regime. Foi entendido que, para um exercício esclarecido da cidadania, era necessário, no mínimo, saber ler, escrever e contar. Assim, assiste-se desde antes da Revolução de 1820 ao aumento da procura da alfabetização por parte de sectores populacionais que visavam a melhoria econômica e a ascensão social.

A Revolução Liberal ficou associada à participação no poder e ao exercício de novas formas de representação escrita. Perspectivando este postulado, a partir da história portuguesa, constatam-se o crescimento e a aceleração da comunicação escrita, manifestos em abaixo-assinados e representações enviadas pelas autoridades locais ao poder central. Um dos assuntos mais estudados reporta à reorganização territorial, judicial e administrativa, tendo como consequência a municipalização e a perda de atribuições por parte de pequenas autarquias. Um segundo assunto, este estudado pela historiografia da educação, respeita ao crescimento de representações públicas e de exposições escritas, com pedidos de criação e 
abertura de escolas, muito particularmente de Escolas de Primeiras Letras. As autoridades municipais procuraram também organizar e disciplinar os diversos tipos de manifestações, que, por vezes, tinham origem em conjuntos de moradores.

As representações camarárias eram dirigidas, em regra, ao Monarca, mas também as houve dirigidas e outros órgãos de soberania. 0 tema dos municípios é transversal. Nesse sentido, e a título de exemplo, refira-se o seguinte caso português. Conhecedora, admita-se, do importante estatuto ocupado pela Junta da Diretoria dos Estudos no quadro de uma modernização governativa centrada na escrita, a Câmara de Abrantes encabeçou uma representação escrita, assinada por dezenas de cidadãos, na qual solicitava à Junta da Diretoria dos Estudos que intercedesse junto do Monarca pela manutenção do Provedor de Abrantes, recordando, entre outros aspectos, "que dos Provedores de Comarca depende a eficácia dos cuidados com a educação e Ensino da Mocidade". ${ }^{14}$ Em consequência, os representantes argumentavam que o referido Provedor tinha revelado prontidão na resposta aos inquéritos e no exame dos opositores, pelo que apelavam à sua manutenção. Datado de 26 de Janeiro de 1821, este documento está assinado pela Câmara, Clero, Nobreza e Povo da vila de Abrantes.

Em Portugal, na transição do Antigo Regime, os municípios cumpriram um papel de representação, como instâncias de soberania local e na relação entre o poder local e o poder central. Senhores de uma tradição, modelo no exercício do poder colegial, com arquivo próprio e com uma escrituração organizada, os municípios não apenas integravam o Estado, como, frequentemente, se assumiam como voz da nação. Na transição do Brasil colônia, os municípios brasileiros integraram o processo de modernização e é possível documentar que houve casos em que se assumiram como agente político do Reino do Brasil e defensores da liberdade.

É nesse sentido que pode ser interpretado o Ato de Vereação extraordinária da Câmara de Caeté, em 7 de Junho de 1822:

Ano do Nascimento de Nosso Senhor Jesus Cristo de mil oitocentos e vinte e dois anos, nesta Vila Nova da Rainha de Nossa Senhora do Bom Sucesso do Caeté minas Comarca do Rio das Velhas, nos paços do Concelho dela, onde presentes se achavam em Acto de Vereação extraordinária o Juiz Ordinário Presidente, o Guardião Mor Geral, João Baptista Pereira de Sousa Coutinho, e mais oficiais da Câmara abaixo assinados, comigo Escrivão do seu cargo ao diante nomeado, para efeito de Despacharem vários Particulares do Serviço

${ }^{14}$ ANTT, Fundo do Ministério do Reino, Secretarias de Estado, Cx. 1125. 
de Deus, da Nação e do Príncipe Regente do Reino do Brasil, e do bem público tudo na forma seguinte: Digo e concorrendo nos mesmos Paços do Concelho, o Juiz dos Órfãos e Almotacé da mesma Vila e Termo com os Homens Bons da Governança, Coronéis comandantes dos Regimentos de Segunda Linha, Reverendo Pároco da freguesia, Clérigos, Oficiais de Segunda e Terceira Linha, e Cidadãos Proprietários que foram convocados pela Câmara, para uma Vereação Extraordinária a instâncias e representações de vários Beneméritos deste Termo para se deliberar sobre o remédio que se deve exigir com urgência do Príncipe [... indecifrável, a parte final da folha está deteriorada...] De se evitarem as desgraças com que somos ameaçados pelo Soberano Congresso de Lisboa, e sendo aí, levantou-se o Coronel José de Sá Bitancurt, e pedindo a palavra fez um eloquente discurso no qual resumiu todos os gravames e atentados cometidos contra a Categoria do Reino do Brasil, contra a sua segurança interna e externa, e contra a sua presente e futura felicidade e pediu em conclusão que a Câmara que representa legalmente todos os habitantes deste Termo, requeresse a Sua Alteza real, o Príncipe Regente a Instalação de Cortes no Brasil para fazerem com melhor conhecimento de causa a Legislação adequada a este Reino, e deliberarem sobre condições mais justas e liberais da união deste Reino, com os de Portugal, e Algarves para cuja execução também devia requerer ao Príncipe Regente que mandasse proceder às novas Juntas Eleitorais, a nomeação de Deputados que no Congresso do Brasil advoguem os nossos foros, Liberdades e franquezas sacrificados a interesses privados e às pretendidas primazias da Metrópole sobre este Reino, quase se fosse de sua Colónia e conformandose toda a Assembleia com o seu voto apoiado pelo comandante interino do Segundo Regimento de Cavalaria Jacinto Peixoto Teixeira [... indecifrável...] Vigário [... indecifrável...] Assembleia [... indecifrável...]. A Sua Alteza Real o Príncipe Regente, e de Funções Perpétuo do Brasil, fundada nestes princípios e associando a Câmara a tão justos Requerimentos de tudo mandou fazer este Termo, que li e assinou-se com toda a Assembleia. ${ }^{15}$

Esta Representação foi assinada pela Câmara, Escrivão, oficiais vários, advogados, clérigos. O termo encerra da seguinte forma: "E na mesma vereação Acordaram em mandar Registar o discurso apresentado pelo Coronel José de Sá Bitancurt". ${ }^{16}$

Como vimos atrás, o Coronel José de Sá Bitancurt tinha já participado na Vereação Extraordinária de 23 de Janeiro de 1816, em que havia sido deliberado proceder à recolha de comparticipações financeiras para a conclusão da estrada que ligava a Sabará. Mas a Vereação Extraordinária de 7 de Junho de 1822 foi convocada com uma ordem de trabalhos que incluía a resposta às Cortes de Lisboa (ao "Soberano Congresso de Lisboa"). Uma vez aberta, a

\footnotetext{
${ }^{15}$ Arquivo Histórico Mineiro, Câmara Municipal de Caeté, Acor 16. Registros de Autos de Vereação, Acórdãos e Termos de Vereança da Câmara Municipal de Caeté, 1822, p. ? [ilegível].

${ }^{16}$ Loc. cit.
} 
sessão foi convertida numa manifestação de desagravo, tendo o Coronel José de Sá Bitancurt proferido um discurso em que apelou à consciência cívica e formulou a proposta concreta de solicitar ao Monarca a constituição de um Parlamento no Brasil. A manifestação de desagravo e de soberania era uma resposta ao Parlamento Constitucional e nela ficou manifesto que o Brasil não se revia nos deputados enviados a Lisboa, nem aceitaria os "gravames e atentados cometidos contra a Categoria do Reino do Brasil", ou seja, a humilhação de ser tratado como colônia. Desde 1815 que o Brasil tinha sido elevado ao estatuto de vice-reinado, mas este manifesto não deixava de ter no horizonte a libertação.

Esta Vereação assim como outras que se seguiram até 7 de Setembro de 1822, quando D. Pedro proclamou a Independência do Brasil, eram assinadas por todos os membros da Câmara e pelas forças vivas locais - assim os proprietários e Homens Bons, as autoridades civis, as autoridades religiosas. Todos acorriam às convocatórias da Câmara, mas também a tomavam como legítima representante. Em face da perspectiva colonialista e conservadora do Parlamento de Lisboa, havia por parte das forças vivas brasileiras um horizonte de reformas, progresso e libertação. Por parte do Município de Caeté, como por parte de outros municípios, havia apelos à sedição na figura de D. Pedro, sobre quem incidiam as expectativas de uma transição legitimada.

Como refere Carlos Mota, ao dar curso e interpretação à "Ideia de Revolução no Brasil e outras ideias", ${ }^{17}$ a questão da propriedade e a revolução estiveram presentes nos debates das ideias, nas sedições e nas Inconfidências que antecederam a Independência. Mas, recorda o mesmo historiador, "nos principais centros urbanos brasileiros aprofundava-se a sensação de abertura para o mundo, de transformação histórica" ${ }^{18} \mathrm{O}$ Brasil estava em contato e compaginado "com a Grécia, a Itália e a Bélgica, num momento em que também a Polônia, a Hungria e a Irlanda buscavam afirmar-se enquanto nações"; havia contatos comerciais "fora do mundo luso-brasileiro, com portos como Barcelona, Baltimore, Bordeaux, Marselha, Liverpool". ${ }^{19}$

Os municípios foram, ao longo do século XVIII e no trânsito do Brasil colônia, instâncias de ordenamento, poder e decisão, por estatuto próprio e por delegação régia. Por exemplo, em 4 de Agosto de 1777, a Câmara de Sabará, consciente das suas obrigações para com a rainha, via-se na necessidade de

\footnotetext{
${ }^{17}$ MOTA, Carlos Guilherme. A Idéia de Revolução no Brasil e outras ideias. $4^{a}$ Edição. São Paulo: Editora Globo, 2008.

${ }^{18}$ Ibidem, p. 406.

${ }^{19}$ Ibidem.
} 
justificar a impossibilidade de contribuir para a reconstrução, pós-terramoto, da cidade de Lisboa, em virtude da situação crítica em que se encontravam as minas de ouro. Ao responder à determinação régia para que esse apoio fosse dado, a Câmara, em representação do povo e como interlocutor legitimado face à Coroa, iniciava a justificação do seguinte modo:

\begin{abstract}
A Vossa Majestade a Câmara da Vila Real de Sabará Capitania de Minas Gerais Estados do Brasil, respeitando ao bem comum, aumento da sociedade, e conservação de um Corpo político, que formaliza, e sustenta a maior parte do Império, ela é, Senhora, que em vezes do povo oferece a seguinte representação, sobre os fundamentos expendidos. As circunstâncias de que esta se reveste; a justiça, e Vezão (sic); estas sublimes qualidades a fazem digna da Real atenção de Vossa Majestade. ${ }^{20}$
\end{abstract}

A centralidade administrativa, de ordenação territorial de jurisdição econômica e de fomento social e cultural, devidamente escriturada, acelerou nas últimas décadas do século. Com a fixação da coroa no Rio de Janeiro, a intervenção pública dos municípios adensou-se e ganhou canais diretos. Essa história está em boa parte documentada nos Arquivos Municipais.

\title{
Escrita e Municipalismo na transição do Brasil-colónia
}

Soberania e progresso são as ideias força do Brasil idealizado e os municípios estão na sua base. Uma vez proclamada a independência, D. Pedro foi de imediato aclamado na Câmara do Rio de Janeiro, para onde se dirigiu. Nos dias seguintes, recebeu manifestações de aclamação e apoio por parte de outras Câmaras, incluindo uma pronta representação da mencionada Câmara de Caeté.

Os municípios tinham sabido converter o elemento escrito em mobilização, modernização, progresso. A escrita, enquanto representação, funcionou na dupla face de registo e de ação (escrever o quê e para quê). Os municípios deram ânimo e sentido às mudanças, congregando e encontrando um lema para a vontade política - sentimento nacionalista. Era necessário disseminar ideias, mas era também necessário formar quadros para o novo Estado moderno e reformista. Foi sugerida a criação de uma universidade, paga pelos municípios.

A governação, a administração e a comunicação municipais eram escritas. Progressivamente, a escrituração municipal passou a integrar

\footnotetext{
${ }^{20}$ REIS, Liliana e VALADARES, Virgínia. Capitania de Minas Gerais em Documentos. Economia, Política e Sociedade. Belo Horizonte: Editora C/Arte, 2012, p. 33.
} 
o consuetudinário, o epistolar, o jurídico, o topográfico, o normalizado e ficou sujeita a pragmáticas. Também comportou uma escrita criativa e transformativa. A aculturação e a escrituração escolar fazem parte desta burocracia e desta modernização. O Brasil independente reservou aos municípios um excepcional e inovador papel no fomento da escolarização. Passou a reger-se pela Constituição de 1824, cujo Artigo 167 estipula que "Em todas as cidades e vilas ora existentes, e nas que para o futuro se criarem, haverá câmaras, às quais compete o governo econômico e municipal das cidades e vilas". ${ }^{21}$ Na sequência, a lei Orgânica do poder municipal, publicada em 1 de Outubro de 1824, consignava no Artigo 70, que as câmaras

(...) terão inspecção sobre as escolas de primeiras letras, educação e destino dos órfãos pobres, em cujo número entrarão os expostos, e quando estes estabelecimentos, e os de caridade, de que trata o artigo 69, se achem por lei, ou de fato, encarregados em alguma cidade ou vila, a outras autoridades individuais ou coletivas, as câmaras auxiliarão sempre quanto estiver da sua parte para a prosperidade e aumento dos sobreditos estabelecimentos. ${ }^{22}$

O Brasil obteve a independência no contexto da Revolução Ocidental. Herdeiros de uma longa tradição, que data das Ordenações Manuelinas e Filipinas, os Municípios brasileiros inscreveram-se de pleno direito e de plena ação na modernização e na construção do Estado moderno e reformista, muito particularmente como senhores da escrita. Os arquivos camarários e o municipalismo são parte dessa história.

Artigo recebido para publicação em 25/10/2014

Artigo aprovado para publicação em 20/11/2014

\footnotetext{
${ }^{21}$ Apud GONÇALVES NETO, Wenceslau e CARVALHO, Carlos Henrique de (org.). o Município e a Educação no Brasil. Minas Gerais na Primeira República. Campinas: Editora Alínea, 2012, p. 27.

${ }^{22}$ Ibidem.
} 